\title{
Pretreatment of super viscous oil wastewater and its application in refinery
}

\author{
Chen Chunmao ${ }^{1}$, Yan Guangxu ${ }^{1}{ }^{*}$, Guo Shaohui ${ }^{1}$ and Yang Yong ${ }^{2}$ \\ ${ }^{1}$ State Key Laboratory of Heavy Oil Processing, China University of Petroleum, Beijing 102249, China \\ ${ }^{2}$ School of Environmental Engineering, Liaoning University of Petroleum \& Chemical Technology, Fushun 113001, \\ Liaoning, China
}

\begin{abstract}
Wastewater from super viscous oil processing cannot be effectively treated by conventional wastewater treatment plants in refineries because of its high concentration of various organic pollutants. In order to resolve this problem, a number of investigations were conducted in our work to understand the physicochemical properties, sedimentation, demulsification and pretreatment of such super viscous oil refinery wastewater. The results showed that the key issues for pretreatment of this wastewater were: (1) Optimized process parameters were used in the sedimentation and demulsification processes for oil removal to effectively recover oil and remove scum from wastewater; (2) A suitable flocculation process was selected to minimize oil, suspended solids (SS) and chemical oxygen demand (CODcr). A pretreatment process including three continuous steps: oil removal by sedimentation, oil removal by demulsification, and flotation separation, was proposed and applied in Liaohe Petrochemical Company, PetroChina and the oil content in effluents was less than $200 \mathrm{mg} / \mathrm{L}$ and CODcr less than 2,500 $\mathrm{mg} / \mathrm{L}$, which completely met the requirement for influent of the conventional wastewater treatment plant, and the recovered super viscous oil reached 5,873 tons in the initial year in Liaohe Petrochemical Company, PetroChina.
\end{abstract}

Key words: Super viscous oil, refinery wastewater, pretreatment process, sedimentation, demulsification, flocculation

\section{Introduction}

In recent years, viscous oil production has increased in China, mainly from Liaohe, Shengli , Karamay and Henan oilfields (Fan et al, 2001; Ji et al, 2002). It was reported that about 30 million tons of super viscous oil were produced and treated in 2005. At present, super viscous oil is processed mainly by atmospheric and vacuum distillation and delayed coking, and the refinery wastewater mainly includes the separated water from the crude oil tank, the wastewater from the electric desalting and calcium removal unit, and the condensed water from the coke cooling steam of the delayed coking unit etc. Compared with the conventional refinery wastewater and the super viscous oil wastewater from the oilfield, the super viscous oil refinery wastewater has a higher content of pollutants, more severe emulsification and special oil-water interface characteristics, which greatly contribute to its stabilization (Fan et al, 2004; Zhang et al, 2006; Pinotti and Zaritzky, 2001; Zouboulis and Avranas, 2000). As an example, about $3 \mathrm{Mt} / \mathrm{a}$ super viscous oil are processed in Liaohe Petrochemical Company, and it was essentially difficult for wastewater treatment process to meet the environmental protection requirements. In September 2004,

\footnotetext{
* Corresponding author. E-mail: yangx0919@163.com

Received June 22, 2007
}

a 1.0 Mt/a delayed coking unit for super viscous oil was put into operation. The emulsified wastewater with a high oil content from the delayed coking process reduces the quality of the primary treatment effluent from oil removal unit and flotation unit of the wastewater treatment plant, beyond the capacity of subsequent biological purification and results in a decrease in the useful microbial population. Finally, the effluent of the wastewater treatment plant seriously exceeds the requirements for discharge. Hence, the super viscous oil wastewater had to be transported out of the refinery to be treated by a contractor, so that the wastewater treatment plant will not be overloaded and the treatment can be improved. However, the treatment of the wastewater by a contractor was expensive, and crude oil could not be recovered from the wastewater. A pretreatment process was developed in our work for treating the super viscous oil wastewater. It was aimed at treating the super viscous oil wastewater from refinery and involved three continuous steps: oil removal by sedimentation, oil removal by demulsification, and flotation separation. The results showed that more than $95 \%$ of oil could be recovered from the wastewater and the effluent could completely meet the influent requirements of the conventional refinery wastewater treatment plant. The feasibility and reliability of the pretreatment process was verified and the pretreatment process was used in a $60 \mathrm{t} / \mathrm{h}$ pretreatment unit of super viscous oil wastewater in Liaohe Petrochemical 
Company, PetroChina.

\section{Materials and methods}

\subsection{Items and methods of analysis}

\subsubsection{Analysis of crude oil}

Refinery wastewater used as the treatment sample was a mixture of three wastewaters, namely the water from super viscous oil tank, the wastewater from electric desalting and calcium removal unit, and the condensed water of coke cooling steam from the delayed coking unit. The wastewater sample was heated at $80^{\circ} \mathrm{C}$ in a water bath to separate the oil. After dehydration the floating oil was analyzed, including, for density, solidifying point, viscosity, resin content, asphalt content, carbon residue, mechanical impurities, and the elemental composition of $\mathrm{C}, \mathrm{H}, \mathrm{S}$ and $\mathrm{N}$. The corresponding analysis methods are reported in literature (Xie, 1987; Pan, 1991).

\subsubsection{Analysis of wastewater}

(1) The mixed sample of three wastewaters was put into a $500 \mathrm{~mL}$ flask after its temperature was measured by mercury thermometer, and kept in a SYP intelligent glass constant-temperature water bath for $12 \mathrm{~h}$, and then the floating oil above the wastewater was removed and the remaining water was analyzed as the initial water as follows: The $\mathrm{pH}$ was measured by a $\mathrm{pH}$ meter according to the Chinese standard GB/6920-86 glass-electrode method and the CODcr was determined by a COD meter according to the Chinese standard GB/11914-89 potassium dichromate method. The oil content was measured by an oil meter with infrared spectrophotometer and the suspended solids (SS) was measured by membrane technology according to the Chinese standard GB/T11901-89 gravimetric determination method.

(2) A specific amount of mixed wastewater sample was diluted tenfold with distilled water, and kept at the initial temperature in a water bath, then it was mixed with cyclohexane and shaken until the organic phase was separated from water. The content of SS in water phase and the content of oil in the organic phase were obtained with Chinese standard GB/T11901-89 gravimetric determination method.

(3) The contents of oil, SS and CODcr were measured by oil meter with infrared spectrophotometer, membrane technology for gravimetric determination and COD meter, respectively, after the wastewater sample was treated by sedimentation, demulsification and flotation.

\subsection{Experimental methods}

\subsubsection{Oil removal by sedimentation}

The wastewater sample was put into a sedimentation tube of organic glass with a diameter of $100 \mathrm{~mm}$, a height of $2500 \mathrm{~mm}$ and 3 sampling points. The sedimentation tube was kept at $80^{\circ} \mathrm{C}$ with electric heating and the wastewater was continuously sampled for measurement in $14 \mathrm{~h}$ with a sampling interval of $2 \mathrm{~h}$. The contents of oil and SS in the height of $100,1,200$ and $2,400 \mathrm{~mm}$ were measured respectively with the methods above.

\subsubsection{Selection of demulsifiers}

First, the wastewater sample was kept for settling for $14 \mathrm{~h}$ in sedimentation tube, then $200 \mathrm{~mL}$ of the wastewater sample was taken and mixed with different demulsifiers of the same amount, separately, and kept at $80{ }^{\circ} \mathrm{C}$ in a water bath for 14 h. Finally, the oil content was measured. It is clear that the higher the oil removal efficiency, the better the demulsifier.

\subsubsection{Flocculant}

Flocculation experiments were carried out with aluminum sulfate as an inorganic flocculant, and hydrolyzed polyacrylamide (HPAM) as an organic coagulant aid due to its macromolecular structure and its good hydrolysis properties. The flocculant dosage and the best ratio of flocculant to coagulant aid were determined. In addition, the stability of the flocculant was investigated.

\section{Results and discussion}

\subsection{Analysis of oil in wastewater}

It is well known that the treatment method for oily wastewater mainly depends on the components and corresponding physicochemical properties of oil residues in wastewater (Guo et al, 2002; Al-Shamrani et al, 2002). The super viscous oil in wastewater used in experiments was from Liaohe Petrochemical Company, PetroChina and its properties are shown in Table 1 . The crude oil has the characteristics of high density $\left(\rho_{20}=1.0122 \mathrm{~g} / \mathrm{cm}^{3}\right)$, high viscosity $\left(v_{100}=821.3\right.$ $\left.\mathrm{mm}^{2} \cdot \mathrm{s}^{-1}\right)$, high solidifying point $\left(32{ }^{\circ} \mathrm{C}\right)$ and high content of resins and asphaltene (more than $26 \%$ by mass). In addition, the resins obtained from the crude oil have high viscosity, dark brown color and density of $1.0 \mathrm{~g} / \mathrm{cm}^{3}$. Meanwhile the crude oil is of low sulfur content, high $\mathrm{C} / \mathrm{H}$ ratio and high carbon residue.

The density changes of super viscous oil and water with temperature are shown in Table 2 and the most suitable temperatures were obtained for sedimentation process and demulsification process for oil removal. The results showed that the density of super viscous oil was less than that of water only when the temperature was higher than $80^{\circ} \mathrm{C}$. It was concluded that the suitable temperature was $80{ }^{\circ} \mathrm{C}$ for both sedimentation and demulsification processes of super viscous oil wastewater.

\subsection{Analysis of wastewater}

The main components of super viscous oil wastewater are shown in Table 3 . The analysis results indicate that the separated water from the super viscous oil tank has the similar characteristics as those from oilfields in pollutants and minerals, including viscous mineral oil, macromolecular polymers, surfactants and inorganic salts (Guo et al, 2002; Bolto et al, 1996; Gulyas and Reich, 1995). Obviously its biodegradation is difficult. While for the wastewater from the electric desalting and calcium removal units, besides those pollutants mentioned above, it also contains calcium removers, including complex compounds, organic acids and inorganic acids, and demulsifying agents, such as PAM. For the condensed water of coke cooling steam from the coking unit, it also contains a high concentration of ammonia nitrogen $\left(\mathrm{NH}_{3}-\mathrm{N}\right)$, volatile hydroxybenzene and sulfides. The oils in super viscous oil wastewater are basically floating 
Table 1 Properties of super viscous oil in wastewater

\begin{tabular}{|c|c|c|c|c|c|c|c|c|c|c|c|}
\hline \multirow{2}{*}{$\begin{array}{c}\rho_{20} \\
\mathrm{~g} \cdot \mathrm{cm}^{-3}\end{array}$} & \multirow{2}{*}{$\begin{array}{c}\text { Solidifying } \\
\text { point, }{ }^{\circ} \mathrm{C}\end{array}$} & \multicolumn{2}{|c|}{$v, \mathrm{~mm}^{2} \cdot \mathrm{s}^{-1}$} & \multicolumn{4}{|c|}{ Components, wt \% } & \multicolumn{4}{|c|}{ Elements, wt \% } \\
\hline & & $80^{\circ} \mathrm{C}$ & $100^{\circ} \mathrm{C}$ & Resins & Asphaltene & $\begin{array}{l}\text { Carbon } \\
\text { residue }\end{array}$ & $\begin{array}{l}\text { Mechanical } \\
\text { impurities }\end{array}$ & $\mathrm{C}$ & $\mathrm{H}$ & S & $\mathrm{N}$ \\
\hline 1.0122 & 32 & 3648.5 & 821.3 & 23.53 & 2.52 & 13.92 & 0.32 & 86.50 & 10.86 & 0.38 & 0.58 \\
\hline
\end{tabular}

Table 2 Densities of super viscous oil and water at different temperatures

\begin{tabular}{ccccccccc}
\hline Temperature, ${ }^{\circ} \mathrm{C}$ & 30 & 40 & 50 & 60 & 70 & 80 & 90 & 100 \\
Density of crude oil, $\mathrm{g} / \mathrm{cm}^{3}$ & 1.0122 & 1.0068 & 1.0004 & 0.9937 & 0.9837 & 0.9695 & 0.9597 & 0.9471 \\
Density of water, $\mathrm{g} / \mathrm{cm}^{3}$ & 0.9956 & 0.9922 & 0.9880 & 0.9832 & 0.9778 & 0.9718 & 0.9653 & 0.9583 \\
\hline
\end{tabular}

Table 3 Contents of main pollutants in super viscous oil wastewater (average value)

\begin{tabular}{ccccc}
\hline Wastewater sample & $\begin{array}{c}\text { Separated water } \\
\text { from super viscous } \\
\text { oil tank }\end{array}$ & $\begin{array}{c}\text { Wastewater from electric } \\
\text { desalting and calcium } \\
\text { removal unit }\end{array}$ & $\begin{array}{c}\text { Condensed water of coke } \\
\text { cooling steam } \\
\text { from coking unit }\end{array}$ & $\begin{array}{c}\text { Mixture of } \\
\text { wastewaters }\end{array}$ \\
\hline Temperature, ${ }^{\circ} \mathrm{C}$ & 70 & 90 & 75 & 7.6 \\
$\mathrm{pH}$ & 8.2 & 6.9 & $\geq 10000$ \\
CODcr, $\mathrm{mg} / \mathrm{L}$ & $\geq 10000$ & 7600 & 3230 & 12010 \\
Content of oil, $\mathrm{mg} / \mathrm{L}$ & 13120 & 14440 & 2240 & 6360 \\
\hline
\end{tabular}

oil, dispersed oil, emulsified oil and soluble oil (Yuan et al, 2000 ), and the corresponding contents are $40.4 \%, 6.1 \%$, $51.7 \%$ and $1.6 \%$ by weight, respectively, with an average oil content of more than $12,000 \mathrm{mg} / \mathrm{L}$. And the floating oil and emulsified oil are the main components of oil in wastewater, worthy to recover and reuse. Along with oil removal, CODcr also decreases greatly. So, the pretreatment process of super viscous oil wastewater is aimed at decreasing oil content and CODcr of wastewater, as well as SS to meet the influent requirements of the conventional wastewater treatment plant.

\subsection{Experiment results}

\subsubsection{Oil removal by sedimentation}

Figs. 1 and 2 show the effects of sedimentation time on the contents of oil and SS in wastewater in three sampling points of $100,1,200$ and $2,400 \mathrm{~mm}$. It was found that most of the floating oil and a few of SS rise up to the top of the sedimentation tube while considerable SS descends to the bottom after a long period of sedimentation. When hydraulic residence time (HRT) was $14 \mathrm{~h}$, almost $50 \%$ of oil in wastewater was recovered and it was mainly floating oil and dispersed oil while the content of emulsified oil did not decrease significantly and was still as high as $6,000 \mathrm{mg} / \mathrm{L}$. As a result, according to the characteristics of high contents of oil and residues in wastewater and high density of oil, oil removal process by sedimentation could use a low load.
Hydraulic loading could be reduced and the oil in wastewater could be recovered as much as possible.

The results showed that HRT was the key issue in the sedimentation process for oil removal. When HRT is in the range of 10-12 h, the oil in wastewater was effectively separated. Longer HRT could make better oil/ water separation, but require a larger volume of tank for oil removal, whereas shorter HRT was not favorable for effectively recovering oil.

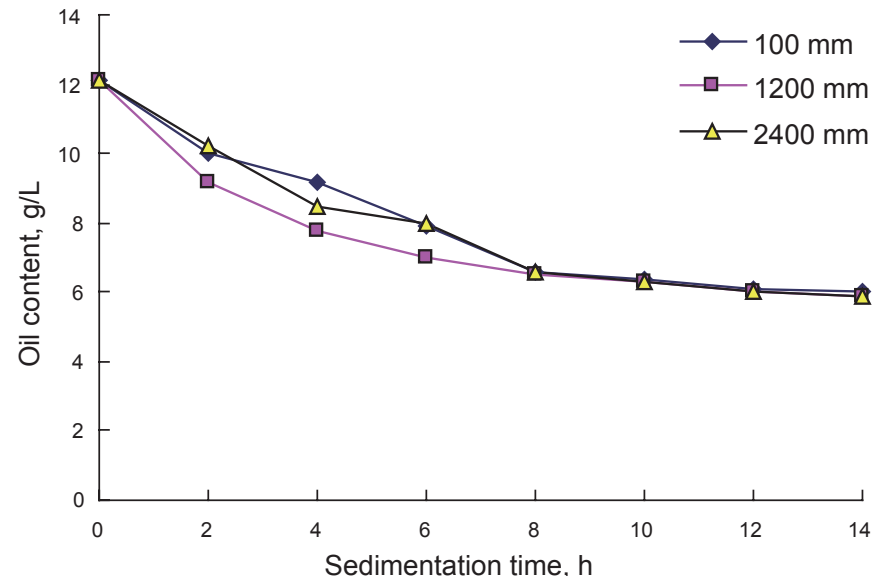

Fig. 1 Relationship between oil content of wastewater and HRT at different sampling heights 


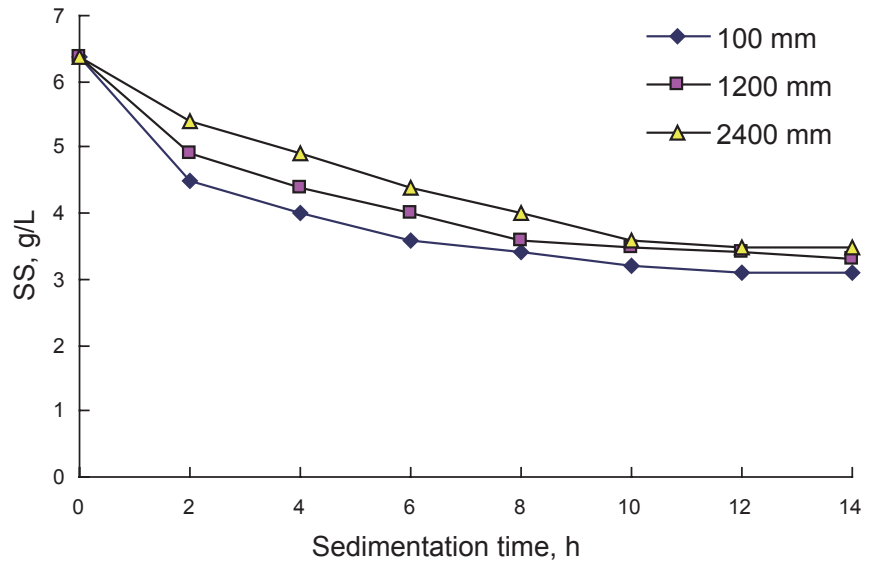

Fig. 2 Relationship between SS of wastewater and HRT at different sampling heights

\subsubsection{Demulsification}

Clearly, there were still lots of oils and SS left in wastewater after the process of oil removal by sedimentation and their contents were 5,000-6,000 $\mathrm{mg} / \mathrm{L}$ and 2,500-3,000 $\mathrm{mg} / \mathrm{L}$, respectively, much greater than influent requirements of the conventional refinery wastewater treatment plant. In addition, the oil left in wastewater was mainly emulsified oil and soluble oil. Hence, a highly effective demulsifier was used to further recover oil and remove pollutants from water. A neutral demulsifier was used to optimize recovered-oil quality and to reduce equipment corrosion. The demulsifier used in our work was synthesized from acrylamide and dimethyl diallyal ammonium chloride (DMDACC) for heavy oil wastewater, particularly for super viscous oil wastewater, with a molecular weight of 6-7 million and cation contents of $40 \%, 60 \%$ and $80 \%$. The results shown in Fig. 3 indicated that the lower the cation content, the better the oil removal and demulsification result at the same amount of demulsifier. And, $40 \%$ of cation content and $15 \mathrm{mg} / \mathrm{L}$ of concentration in wastewater were suitable for the demulsifier. The results showed that the oil content of water was below $600 \mathrm{mg} / \mathrm{L}$ after demulsification treatment and more than $65 \%$ of SS were removed and sludge appeared at the bottom of the beaker. Considering the density and other properties of super viscous oil in wastewater, sedimentation time after demulsification treatment was still selected to be $10-12 \mathrm{~h}$.

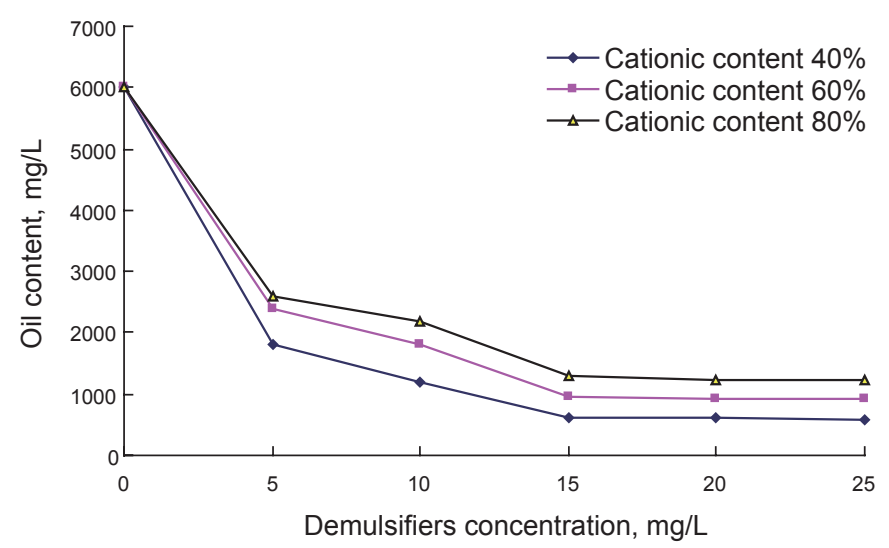

Fig. 3 Oil content of water after demulsification treatment with different demulsifiers

\subsubsection{Flocculation}

After demulsification treatment, wastewater still contained some emulsified oil, soluble oil, SS, etc, and the oil content, SS and COD were respectively $500-600 \mathrm{mg} / \mathrm{L}$, more than $800 \mathrm{mg} / \mathrm{L}$ and 2,000-3,000 $\mathrm{mg} / \mathrm{L}$, still higher than influent requirements of the conventional wastewater treatment plant. In the experiment, aluminum sulfate was selected as the flocculant and its dosage was in the range of 200-300 $\mathrm{mg} / \mathrm{L}$ (Zhang et al, 2005; Rubio et al, 2002). The optimum dosage was $250 \mathrm{mg} / \mathrm{L}$, which was twice the amount used in conventional wastewater treatment plant. And the suitable dosage of organic coagulant aid HPAM was in the range of 2-4 mg/L. Larger dosage would worsen the biodegradability of the wastewater with low biochemical oxygen demand (BOD) and affect the subsequent bio-treatment (Guo et al, 2002). Finally, $2 \mathrm{mg} / \mathrm{L}$ of HPAM was used in consideration of COD, oil content and SS in wastewater effluent.

Figs. 4, 5 and 6 show the oil content, CODcr and SS in wastewater before and after flocculation treatment with different wastewater samples, respectively. It was shown that the oil content, CODcr and SS in wastewater were less than $100 \mathrm{mg} / \mathrm{L}$, below $1,500 \mathrm{mg} / \mathrm{L}$ and about $400 \mathrm{mg} / \mathrm{L}$ respectively after flocculation treatment, greatly decreased compared with those before flocculation treatment.

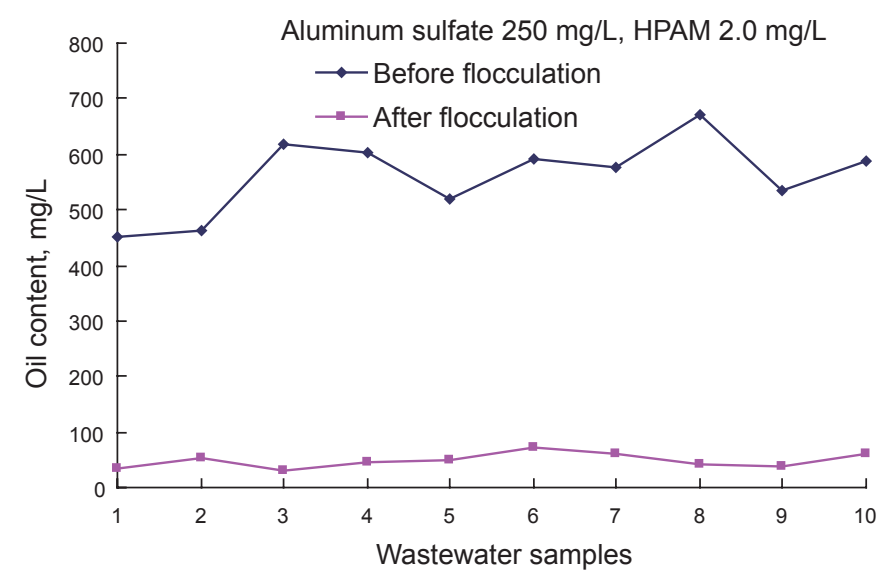

Fig. 4 Oil content in wastewater before and after flocculation treatment

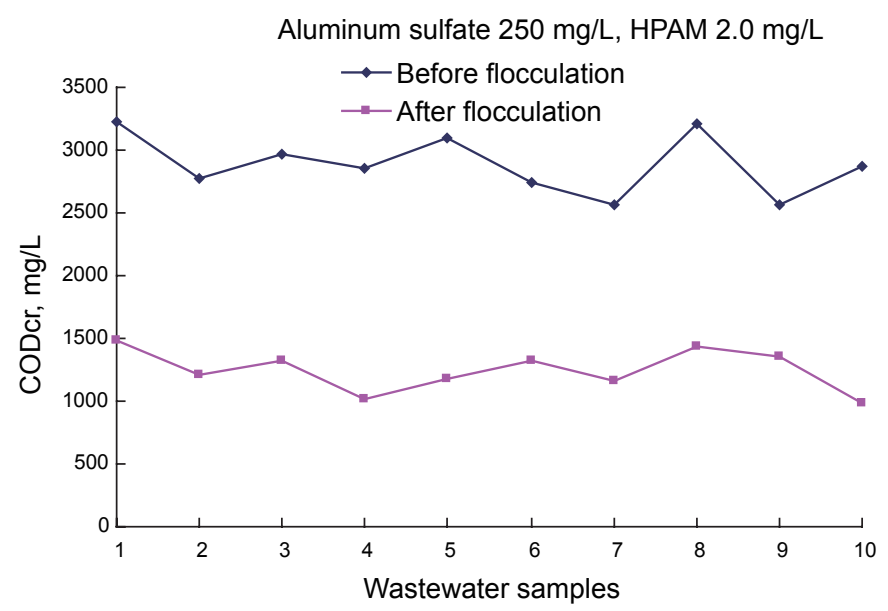

Fig. 5 COD in wastewater before and after flocculation treatment 


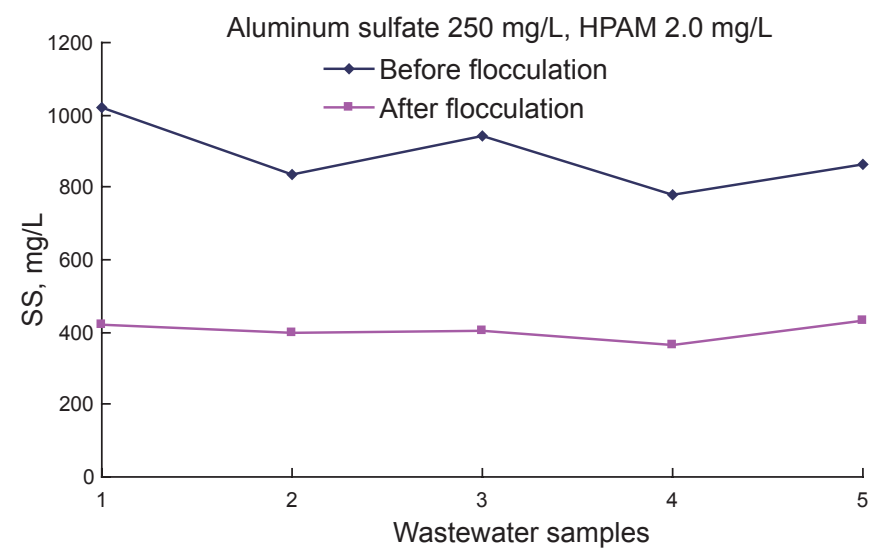

Fig. 6 SS in wastewater before and after flocculation treatment

\section{Application examples}

A $60 \mathrm{t} / \mathrm{h}$ pretreatment unit for super viscous oil wastewater was constructed in 2005 at Liaohe Petrochemical Company, PetroChina with its technological process and parameters based on the experiments we have done. The total investment reached 7 million $¥ \mathrm{RMB}$ including equipment and infrastructure. The pretreatment unit was put into operation on Dec.15th 2005, and during the year until December 2006, $133,795.7 \mathrm{~m}^{3}$ wastewater were treated and 5,873 tons super viscous oil was recovered. Considering the chemicals and power consumption, the cost of wastewater treatment were $7.04 ¥ \mathrm{RMB} /$ ton and 0.9416 million $¥ \mathrm{RMB} /$ year, and the profit was 8.8095 million $¥ \mathrm{RMB}$ by recovering super viscous oil $(1,500 ¥ \mathrm{RMB} /$ ton $)$. The cost of 1.5 million $¥$ $\mathrm{RMB} /$ year for treatment by contractor was saved. The total economic benefit reached 99.3679 million $¥ \mathrm{RMB} /$ year.

\subsection{Process of pretreatment of super viscous oil wastewater}

The pretreatment process for super viscous oil wastewater mainly includes three steps: Oil removal by sedimentation, oil removal by demulsification, and flotation separation. The corresponding process flow and the main equipment are shown in Fig. 7 and Table 4, respectively.

The characteristics of the process flow are as follows:

1) Super viscous oil wastewater is first gathered into the sedimentation tank to remove sludge, floating oil and dispersed oil. This sedimentation tank also acts as a buffer to ensure the steady quality of wastewater for the whole pretreatment process;

2) The effluent from the sedimentation tank is fully mixed with demulsifier and pumped into demulsification-

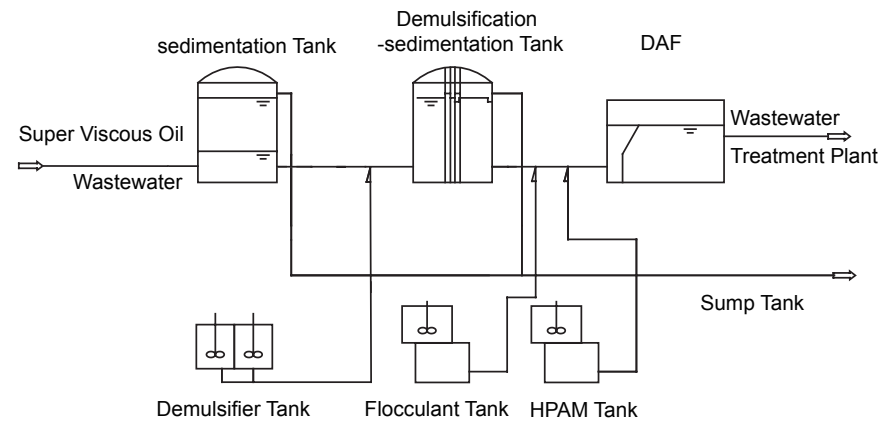

Fig. 7 Pretreatment process of super viscous oil wastewater, used in Liaohe Petrochemical Company, PetroChina

sedimentation tank, and then the demulsified oil is separated from wastewater and recovered.

3) The effluent from the demulsification-sedimentation tank is mixed with flocculant and HPAM and pumped into the dissolved air flotation machine (DAF) for the final step of pretreatment and then the wastewater is sent to the conventional wastewater treatment plant.

In addition, the temperature of the whole pretreatment process is maintained at $75-85{ }^{\circ} \mathrm{C}$ and the related pipelines are heat-insulated. A sump tank is equipped to collect the recovered oil from sedimentation tank and demulsificationsedimentation tank, whereas the sludge and SS produced in the pretreatment process are collected in sludge pool and periodically transported to the oily sludge treatment system in the conventional wastewater treatment plant.

\subsection{Application example}

Figs. 8 and 9 show the quality of super viscous oil wastewater after pretreatment process during the first half

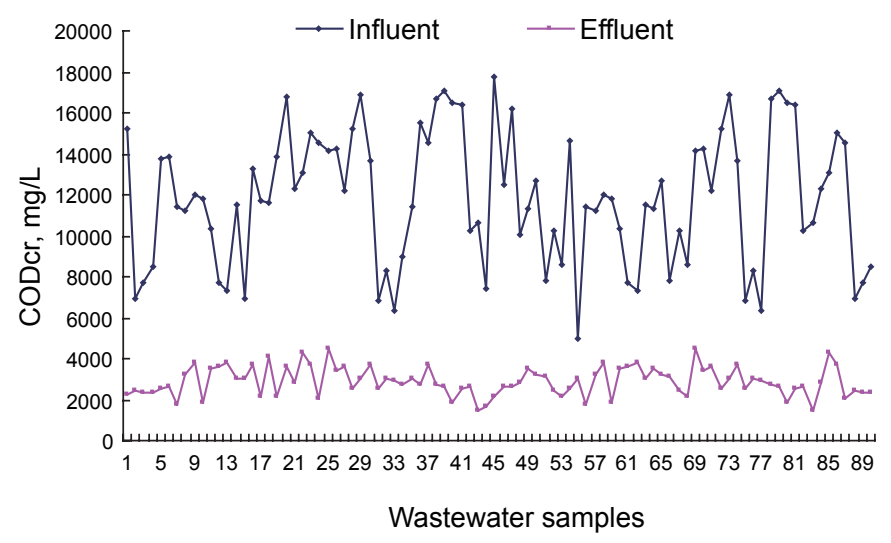

Fig. 8 CODcr content in wastewater before and after pretreatment process

Table 4 Main equipment and specifications

\begin{tabular}{ccccc}
\hline No. & Equipment & Type and standard & Number & Note \\
\hline 1 & Sedimentation tank & $1000 \mathrm{~m}^{3}$ & 1 & Heat insulated \\
2 & Demulsification-sedimentation tank & $1000 \mathrm{~m}^{3}$ & 1 & $\begin{array}{c}\text { Heat insulated } \\
\text { Dissolved air pump } \\
\text { and sludge scraper }\end{array}$ \\
\hline
\end{tabular}




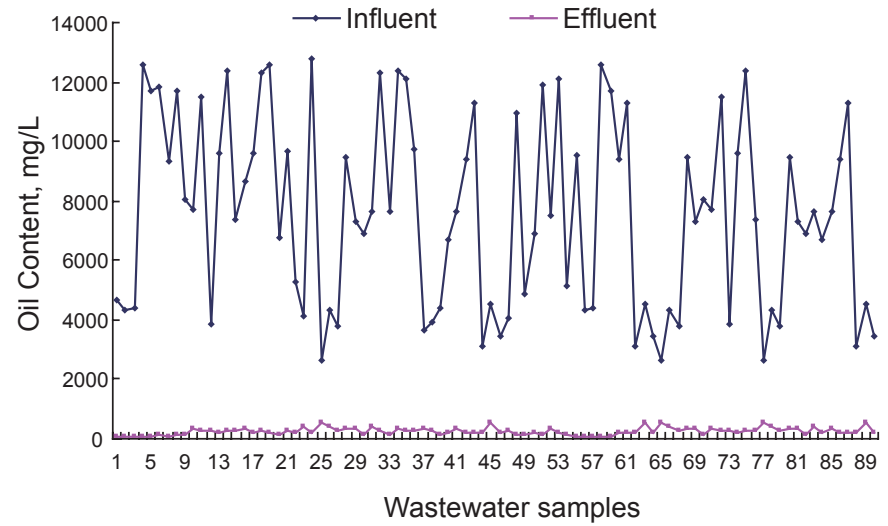

Fig. 9 Oil content in wastewater before and after pretreatment process

of 2006. With strong fluctuation, the average oil content and CODcr in raw wastewater were more than $12,000 \mathrm{mg} / \mathrm{L}$ and $10,000 \mathrm{mg} / \mathrm{L}$ respectively, but the oil content and CODcr were less than $200 \mathrm{mg} / \mathrm{L}$ and $2,500 \mathrm{mg} / \mathrm{L}$, respectively, after pretreatment process. It is concluded that the effluent from the pretreatment process can meet the influent requirements of the conventional wastewater treatment plant.

\section{Conclusions}

1) The experiment results showed that most floating oil and dispersed oil could be recovered when the sedimentation HRT was kept more than $12 \mathrm{~h}$ and more than $90 \%$ of emulsified oil could be recovered after the demulsification process. And COD and SS could decrease greatly through the flocculation treatment. According to the characteristics of high contents of crude oil and residues in wastewater and of high density of oil, a low loading could be used in the sedimentation process and demulsification process to recover as much oil as possible from wastewater

2) The application of the super viscous oil wastewater pretreatment process which was designed based on our experiments achieved good effluent quality, realizing the goal of recovering oil from wastewater and controlling the quality of wastewater for subsequent treatment. The oil content in wastewater was less than $200 \mathrm{mg} / \mathrm{L}$ and CODcr was less than $2,500 \mathrm{mg} / \mathrm{L}$ after the pretreatment process.

\section{References}

Al-Shamrani A A, James A and Xiao H. Destabilisation of oil-water emulsions and separation by dissolved air flotation. Water Research. 2002. 36: 1503-1512

Bolto B A, Dixon D R, Gray S R, et al. The use of soluble organic polymers in waste treatment. Water Sci. Tech.1996. 34(9): 117-124

Fan W Y, Song Y M and Nan G Z. Study on stability of heavy crude oilin-water emulsion: I. Interfacial viscosity for the system of Liaohe heavy crude functional components and water. Acta Petrolei Sinica (Petroleum Processing Section). 2001. 17 (Supplement): 1-8 (in Chinese)

Fan W Y, Song Y M and Nan G Z. Effects of different heavy crude oil fractions on the stability of oil-in-water emulsions-isolation of functional fractions from heavy crude oil and study of their properties. Petroleum Science. 2004. 1(3): 66-71

Gulyas H, Reich M. Organic compounds at different stages of a refinery wastewater treatment plant. Water Sci. Tech. 1995. 32(7): 119-126

Guo S H, Bai Y X and Zhang H R. Study on Pretreatment Process of Super Viscous Oil Emulsion Wastewater. Research of Environmental Sciences. 2002. 15(1): 1-5 (in Chinese)

Ji G D, Sun T H, Zhou Q X, et al.. Constructed Subsurface Flow Wetland for Treating Heavy oil-produced Water of the Liaohe Oilfield in China. Ecological Engineering. 2002. 18: 459-465

Pan C E. Petroleum Analysis. Shanghai: East China of Science and Technology Press. 1991 (in Chinese)

Pinotti A and Zaritzky N. Effect of aluminum sulfate and cationic polyelectrolytes on the destabilization of emulsified wastes. Waste management. 2001. 21: 535-542

Rubio J, Souza M L and Smith R W. Overview of flotation as a wastewater treatment technique. Minerals Engineering. 2002. 15: 139-155

Xie C G. Analysis Technology of Petroleum Pollutions in Environment. Beijing: China Environmental Science Press. 1987 (in Chinese)

Yuan H X, Yu J F and Cai X H. Application prospect of hydrocyclone in treatment of oily Water. Petroleum Refinery Engineering. 2000. 30(5): 48-51(in Chinese)

Zhang J C, Wang Y H, Song L F, et al. Feasibility investigation of refinery wastewater treatment by combination of PACs and coagulant with ultrafiltration. Desalination. 2005. 174: 247-256

Zhang T Y, Fan W Y and Nan G Z. Study on Interaction of Heavy Crude Oil Polar Components and Emulsifier in Heavy Crude Oil-in-water Emulsions. Journal of China University of Petroleum. 2006. 30(5): 101-105 (in Chinese)

Zouboulis A I and Avranas A. Treatment of oil-in-water emulsions by coagulation and dissolved-air flotation[J]. Colloids and Surfaces. A: Physicochemical and Engineering Aspects. 2000. 172: 153-161

(Edited by Zhu Xiuqin) 